\title{
Aborto legal y justicia reproductiva. Reseña de Interrupción del embarazo desde la experiencia de las mujeres: aportaciones interdisciplinarias
}

Legal Abortion and Reproductive Justice. Review

of Interrupción del embarazo desde la experiencia de las mujeres: aportaciones interdisciplinarias

Fecha de recepción: 06/09/2021

Fecha de aceptación: 08/11/2021

Fecha de publicación: 07/03/2022

https://doi.org/10.48102/if.2022.v2.n1.197

Círculo Feminista Alaíde Foppa*

circuloalaidefoppa@gmail.com

México

Palabras clave

Aborto, experiencia, mujeres, justicia reproductiva, Latinoamérica, feminismo.

Keywords

Abortion, experience, women, reproductive justice, Latin America, feminism.

* El Círculo Feminista Alaíde Foppa es una organización feminista de Toluca, Estado de México, que tiene como objetivos generar un espacio de reflexión en torno a la reivindicación de los derechos de las mujeres y promover el desarrollo de proyectos académicos y culturales de corte feminista. 
Cedeño Peña, L. y Tena Guerrero, O. (coords.) (2020). Interrupción

del embarazo desde la experiencia de las mujeres: aportaciones

interdisciplinarias. Universidad Nacional Autónoma de México.

\section{Introducción}

Resulta muy significativo que un tema como el aborto, históricamente silenciado, hoy aparezca reiteradamente en los medios de comunicación, en las publicaciones científicas e incluso en los discursos políticos; esta visibilidad, como señaló Carlos Monsiváis en 1991 (cuando se empezaba a hablar sobre aborto en los medios), es un campo ganado en la lucha por la despenalización (Monsiváis, 1991, p. 2).

Sin embargo, si bien es fundamental posicionar el tema, la manera en que éste se plantea es un aspecto clave. La demanda de despenalización tiene una historia que se remonta a los años treinta (Lamas, 2017, p. 11), pero es muy interesante observar cómo, con el paso del tiempo, los argumentos en los que se basa dicha demanda se han ido transformando: se ha transitado de razones exclusivamente vinculadas a la salud, la pobreza y la discriminación a temas de libertad sobre el propio cuerpo y derechos reproductivos.

La posibilidad de recuperar, tanto en el espacio académico como en el ámbito del activismo, la experiencia de las mujeres ha permitido ampliar el espectro de visión y ha sido una variable fundamental para que el discurso en torno a la interrupción voluntaria del embarazo se plantee cada vez con más frecuencia en términos de justicia reproductiva y soberanía sobre el cuerpo.

Prueba de ello es Interrupción del embarazo desde la experiencia de las mujeres: aportaciones interdisciplinarias (2020), libro coordinado por Lurel Cedeño Peña y Olivia Tena Guerrero, que intenta, a través de la reflexión en torno a la experiencia de quienes deciden abortar, activar la discusión sobre el cuerpo como territorio de resistencia y como vehículo para la demanda de derechos y el ejercicio de libertades.

El libro -que, como se señaló, enfatiza la experiencia de las mujeresestá organizado en tres secciones y se concentra en la región de América Latina y el Caribe, en donde, según el último reporte del Instituto Guttmacher (2018), el $32 \%$ de los embarazos terminaron en aborto, pero sólo uno de cada cuatro fue seguro. A propósito de ello, las autoras subrayan que existe suficiente evidencia a nivel internacional para sostener que la despenalización del aborto se traduce en una reducción de la mortalidad materna. 
Las investigaciones compiladas en la publicación tienen el objetivo de contribuir a las reflexiones sobre la interrupción del embarazo desde múltiples enfoques, visibilizar temas novedosos en torno al fenómeno, además de mostrar los avances que han logrado las organizaciones feministas.

Lurel Cedeño y Olivia Tena se proponen, también, identificar los obstáculos y desafíos actuales de la agenda por un aborto seguro, legal y gratuito en América Latina y el Caribe. Plantean los escenarios complejos a los que se enfrentan las mujeres que deciden interrumpir su embarazo en la región, tanto en el plano puramente legal como en el simbólico. Cedeño, Tena y las autoras que participan en el libro subrayan las tareas pendientes en términos de despenalización y servicios de salud necesarios para la interrupción del embarazo, así como en materia de desestigmatización de dicha práctica.

\section{Desarrollo}

La primera sección está conformada por dos capítulos: el primero es "Aborto legal y derecho a la salud" de Lucía Melgar, Susana Lerner y Agnès Gillaume; el segundo trabajo es de Emanuela Borzacchiello, "El aborto como práctica de control social y el cuerpo como territorio de resistencia". Se puede intuir, desde los títulos, que son investigaciones que discuten en la arena de los derechos y la lucha por la libertad de elegir. El primer documento se centra en el derecho a la salud de las mujeres como argumento para la legitimación de la despenalización del aborto; el segundo reivindica la interrupción legal del embarazo como un tema primordial de la agenda feminista.

Lucía Melgar, Susana Lerner y Agnès Guillaume enfatizan la necesidad de ampliar las definiciones de salud reproductiva y salud pública: ${ }^{1}$ presentan datos de la Organización Mundial de la Salud (OMS) y la Asociación Psiquiátrica Americana (APA) que niegan la relación directa de aborto legal y seguro con depresión u otras afecciones emocionales en las mujeres, y subrayan los beneficios que el acceso a la interrupción legal del embarazo tiene para la salud y autonomía de éstas.

El aporte de este tipo de investigación al campo de la reflexión sobre aborto es fundamental porque, por un lado, desmonta el mito de la de-

1 Proponen partir del concepto "salud" de Alejandro Jadad: "la capacidad de las personas o de las comunidades para adaptarse a, o para autogestionar los desafíos físicos, mentales o sociales que se le presenten en la vida" (en Melgar et. al., 2020, p. 32).

Círculo Feminista Alaíde Foppa (2022). Aborto legal y justicia reproductiva. Reseña de Interrupción del embarazo desde la experiencia de las mujeres: aportaciones interdisciplinarias. Iberoforum, Revista de Ciencias Sociales, Nueva Época, 2(1), 1-9, Reseñas, e000195. https://doi.org/10.48102/if.2022.v2.n1.197 Licencia Pública Internacional - CC BY-NC-ND 4.0 
presión o la angustia vinculado exclusivamente a la práctica del aborto y explica cómo las emociones negativas responden más al estigma asociado con el aborto que a la práctica misma. Por otro lado, aporta información en torno al hecho de que practicar un aborto en las condiciones óptimas no sólo reduce drásticamente el riesgo de muerte en las mujeres, sino que se traduce en sensaciones positivas de libertad e independencia.

Emanuela Borzacchiello, por su parte, en "El aborto como práctica de control social y el cuerpo como territorio de resistencia", se pregunta ¿por qué, con toda la brutalidad y la violencia que se vive en México, el aborto tendría que seguir siendo un tema prioritario para la agenda política feminista? Para responder a ello, recupera la construcción del discurso sobre aborto a través de lo visual, lo textual y la propia mirada política feminista.

Respecto al plano visual, Borzacchiello analiza cómo el discurso en torno al aborto está cargado de una serie de prejuicios que se sirvieron del surgimiento de la ecografía para construir la imagen del feto o embrión como una persona y generar una discusión pública en torno a un espacio de decisión tan privado e íntimo como el vientre.

Desde el plano textual, muestra cómo en la narrativa del aborto las mujeres son silenciadas o hiper-visibilizadas. Por un lado, existe una exposición pública de quienes deciden abortar: se emiten juicios sobre ellas, se discute abiertamente en torno a cuáles son los caminos que debieron haber tomado, se les estigmatiza explícitamente. Por otro lado, hay una demanda implícita de silencio: las mujeres que abortan no hablan públicamente sobre ello porque hacerlo generaría un impacto en su reputación que tendría efectos negativos en términos de su "credibilidad" o "valor social".

Los movimientos feministas señalan todas esas violencias y contradicciones; según Borzacchiello, "afirman la [...] importancia de una mirada crítica del sistema de relaciones en las que estamos insertas" (en Cedeño y Tena, 2020, p. 59), llaman a no confundir la soberanía de la mujer sobre su cuerpo con la omisión estatal de una serie de responsabilidades que tienen que ver con el cuidado de la vida y de la salud.

La segunda sección del libro inicia con un capítulo de profunda relevancia: "La legalización del aborto voluntario en Uruguay: nuevas interrogantes a partir de las experiencias de las mujeres", escrito por Alejandra López Gómez, Martín Couto Gómez y Lilián Abracinskas. Las autoras presentan una reflexión del proceso de legalización del aborto voluntario en Uruguay; en ella, enfatizan el conflicto entre el marco normativo y la prác- 
tica social. A pesar de que en 2012 el Parlamento uruguayo aprobó la ley No. 18.987 sobre Interrupción Voluntaria del Embarazo (IVE) en las doce primeras semanas de gestación, en el artículo $1^{\circ}$ de dicha ley se establece que "el Estado garantiza el derecho a la procreación consciente y responsable, reconoce el valor social de la maternidad, tutela la vida humana y promueve el ejercicio pleno de los derechos sexuales y reproductivos de toda la población".

La redacción misma del párrafo ya genera escepticismo, pues es claro que enfatizar el valor social de la maternidad contribuye a reforzar el mandato tradicional de ésta. Como si eso no fuese suficiente, la reglamentación de la IVE establece la obligatoriedad de tres consultas previas al aborto y una posterior; en la segunda, la mujer debe comunicar los motivos por los que quiere interrumpir el embarazo; luego, debe esperar cinco días antes de volver a los servicios de salud para decidir si ratifica su decisión de abortar o elige continuar con el embarazo. Sumado a ello, está el hecho de que la ley ampara la objeción de conciencia para los médicos y ginecólogos, así como la objeción por ideario para los efectores de salud que decidan no instrumentar directamente los servicios.

Todo esto es una muestra clara de que, para hacer efectivos los derechos reproductivos de las mujeres, no es suficiente la despenalización del aborto, sino que es necesario un trabajo de desestigmatización de dicha práctica que permita el diseño de marcos normativos verdaderamente progresistas, que respalden a las mujeres y no intenten desalentarlas o hacerlas dudar de las decisiones que toman sobre sus cuerpos.

El siguiente capítulo del libro, "Estigma y aborto: experiencias de mujeres y personal de salud en los servicios de ILE en la Ciudad de México", de Ma. Elena Collado Miranda y Jazmín Mora Ríos, explora los efectos del estigma vinculado al aborto en tres sectores específicos: 1) las mujeres que han tenido un aborto, 2) los proveedores de este servicio de salud y 3) personas que apoyan a mujeres que han tenido abortos.

Las mujeres que han accedido a la interrupción legal del embarazo (ILE) en la Ciudad de México (CDMX) son blanco de críticas basadas en prejuicios y estereotipos negativos; se les asigna atributos relacionados con la promiscuidad, la irresponsabilidad y el descuido; además, se les asocia con un pronóstico fatalista bajo la idea de que algo muy malo les ocurrirá, como una suerte de castigo por elegir interrumpir su embarazo. 
Respecto al personal de salud que trabaja en clínicas ILE, el estigma se traduce en frases discriminatorias o en acciones violentas por parte de sus colegas de trabajo e, incluso, por parte de familiares. Lo mismo sucede con las personas que apoyan a mujeres que han decidido abortar: son blanco de críticas y descalificaciones por incurrir en una práctica legalmente plausible pero socialmente estigmatizada. Esto abre la reflexión en torno a que, si bien en términos legales el aborto es una práctica aceptada y regulada en la CDMX, la construcción simbólica que se hace de ésta es una tarea pendiente que se debe de atender con urgencia.

El último capítulo de la segunda sección, "Estigma y empoderamiento en los itinerarios abortivos de mujeres mexicanas", escrito por Lurel Cedeño Peña y Olivia Tena Guerrero, insiste en la renovación a la que apuntamos con el título de esta reseña; a saber, la práctica del aborto como un derecho de las mujeres y un tema de justicia reproductiva.

Cedeño y Tena subrayan un elemento fundamental en torno al proceso de la IVE: el empoderamiento de las mujeres. Si bien los itinerarios abortivos implican una serie de obstáculos que deben librarse, las autoras encontraron que la mayoría de las mujeres que concluyen el proceso afirman sentirse tranquilas y liberadas con la decisión que tomaron, pues han asumido el control sobre sus cuerpos y sus vidas.

El discurso antiderechos se ha empeñado en vincular el aborto con la depresión y el trauma; una de las tareas del feminismo es ofrecer evidencia que permita desmontar este mito. La tristeza, la depresión, la angustia son condiciones que experimentamos en diversos momentos de nuestra vida por múltiples razones; asociarlas exclusivamente a la práctica del aborto es una trampa del patriarcado, que se sirve de imágenes exageradas y caricaturizadas para satanizar la interrupción del embarazo.

La narrativa que sataniza el aborto es la misma que mitifica la maternidad y la presenta como un ejercicio de absoluto placer y disfrute. Si bien para muchas mujeres maternar es un motivo de satisfacción y felicidad, para otras no. La sociedad patriarcal en la que vivimos no sólo excluye del relato público el hecho de que para algunas mujeres la maternidad no sea una opción, sino que convierte en tabú el hecho de que interrumpir embarazos no deseados es, para muchas, un motivo de alegría y una ruta de empoderamiento.

Lurel Cedeño y Olivia Tena subrayan el fenómeno que el patriarcado intenta borrar: el aborto no es necesariamente una experiencia de dolor y angustia; gracias al apoyo de las organizaciones feministas, a las redes 
de amigas, a la información de primera mano brindada por mujeres que han interrumpido su embarazo, abortar puede ser una práctica segura que permita a las mujeres empoderarse.

La tercera parte del libro inicia con un capítulo que plantea una mirada muy novedosa del fenómeno de la IVE: "La decisión de abortar en el segundo trimestre del embarazo", escrito por Nayla Luz Vacarezza y Ruth Zurbriggen. Las autoras ponen sobre la mesa un tema que es poco discutido, incluso en el ámbito del feminismo y los discursos más progresistas en torno a la soberanía de las mujeres sobre sus cuerpos.

Vacarezza y Zurbriggen trazan hipótesis sobre las razones que llevan a que algunas mujeres decidan y necesiten abortar en el segundo trimestre del embarazo; incorporan variables como educación sexual, violencia de género, condiciones de vida precarias e, incluso, factores subjetivos que pueden hacer que las mujeres demoren la confirmación del embarazo.

Las investigadoras enfatizan que la decisión de abortar puede ser un proceso que lleve cierto tiempo, especialmente para mujeres en posiciones de mayor vulnerabilidad social o que son víctimas de violencia; en este sentido, el discurso por la despenalización debe replantearse o, al menos, discutir el tema de las doce semanas.

El último capítulo del libro, "ADAS, un camino para renovar la fortaleza emocional después de un aborto voluntario", de Olivia Ortíz Ramírez, recupera la relevancia de los aportes de los estudios feministas en torno a las emociones, enfatiza el carácter social de éstas y señala la importancia de recuperar la experiencia emocional en el discurso sobre interrupción del embarazo.

La autora afirma que existe evidencia de que la presencia de redes de apoyo en torno a la vida de las mujeres ha facilitado la resolución de múltiples conflictos; explica cómo, a pesar de que existen pocos trabajos sobre acompañamiento postaborto, la atención y contención emocional son tareas fundamentales.

El texto ofrece datos en torno al trabajo específico de Acompañamiento Después de un Aborto Seguro (ADAS), que desde 2007 ha brindado apoyo a más de 150 mujeres y que ha desarrollado una metodología integral para llevar a cabo dicha labor; además, presenta una afirmación contundente: "de todas las reacciones emocionales [...] expresadas [...] por las mujeres [...] el alivio al final del procedimiento clínico es una de las constantemente referida" (Goodwin y Ogden, en Cedeño y Tena, 2020, p. 233). 
Es decir, con el trabajo de Ortíz, aparece una vez más el tema de las emociones positivas vinculadas a los procesos de interrupción del embarazo; esto no es sólo un argumento más en la lucha por la despenalización, sino una enorme contribución a la construcción de un nuevo discurso en torno al fenómeno, que pone el acento en la libertad, y el ejercicio pleno de la vida y libertad de las mujeres.

\section{Conclusiones}

El libro es un aporte fundamental a la reflexión científica sobre interrupción voluntaria del embarazo pues ofrece argumentos para desmontar mitos como la maternidad como destino o la depresión postaborto; subraya, a través de la experiencia de diversas mujeres, cómo el aborto voluntario puede ser un ejercicio de empoderamiento y autonomía.

Los textos presentados permiten comprender que América Latina es una región que tiene mucho trabajo pendiente en materia de legalización y desestigmatización de la interrupción del embarazo, aunque las redes de apoyo feminista y la atención de las emociones también permiten dar pasos hacia adelante en el camino de la soberanía de las mujeres sobre sus cuerpos y sus vidas.

Los capítulos que componen el libro subrayan la capacidad crítica de la mirada feminista y arrojan luz sobre la ruta que podrían tomar los países que caminan hacia la legalización del aborto; la discusión de casos como los de Uruguay o la CDMX brindan recursos que pueden servir para el diseño de estrategias cada vez más progresistas y de respeto a la libre elección de las mujeres.

Nos atrevemos a señalar que, sólo en la medida en que se comprenda el aborto como un tema de derechos humanos de las mujeres, se podrá diseñar marcos normativos que no se limiten a "cumplir" la demanda pública de aborto, sino que verdaderamente asuman dicha práctica como un ejercicio de libertad y justicia reproductiva.

\section{Referencias bibliográficas}

Cedeño Peña, L. y Tena Guerrero, O. (coords.) (2020). Interrupción del embarazo desde la experiencia de las mujeres: aportaciones interdisciplinarias. Universidad Nacional Autónoma de México.

Instituto Guttmacher (2018). Aborto en América Latina y el Caribe. https://www. guttmacher.org/es/fact-sheet/aborto-en-america-latina-y-el-caribe 
Lamas, M. (2017). La interrupción legal del embarazo. El caso de la Ciudad de México. Fondo de Cultura Económica, Universidad Nacional Autónoma de México.

Monsiváis, C. (1991, 1 de marzo). De cómo un día amaneció Pro-Vida con la novedad de vivir en una sociedad laica. Debate Feminista, 3. https:// doi.org/https://doi.org/10.22201/cieg.2594066xe.1991.3.1498 